\title{
Having Distance Learning Means Getting Distance Knowledge for Higher Education Students in Indonesia
}

\author{
Satria Agust ${ }^{1 *}$, Gatot Subroto $^{2}$, Cellia Utami ${ }^{3}$, Safhira Ramadhanti ${ }^{4}$, Nadia Pratiwi $^{5}$, Tia \\ Wahyuni ${ }^{6}$ \\ \{ satria.agust@umrah.ac.id ${ }^{1}$, gatot.subroto@umrah.ac.id ${ }^{2}$, 180388203024@ student.umrah.ac.id ${ }^{3}$ \} \\ ${ }^{1,2,3,4}$ Department of English Education, Faculty of Teacher Training and Education, \\ Universitas Maritim Raja Ali Haji, Tanjungpinang, Riau Islands, Indonesia
}

\begin{abstract}
Distance learning has been becoming the new learning systems for the universities which always deal with offline class during the coronavirus outbreak. In this paper, the researchers aimed to analyze the disadvantages in distance learning. This study examined the distant experiences through the Indonesian college students' points of view. The researchers used a qualitative research method. The research data were collected online through social media platforms i.e., Twitter and WhatsApp. They were in the forms of interviews in questionnaires related to students' experiences engaging in distance learning. The subjects were 55 college students from various universities in Indonesia. The results were (1) the disadvantages of distance learning wee various, (2) the obstacles that most experienced by the students were poor internet connection, and lack of internet data, and (3) the obstacles which they experienced led to the distance knowledge which really affected their learning processes. These conditions implicitly say that traditional classroom students have not been ready for the distance learning which brings them to distance knowledge and learning lost.
\end{abstract}

Keywords: Distance learning, disadvantages, obstacles, college students

\section{Introduction}

Due to the coronavirus outbreak, all social activities have been being shut down all over the world. Some countries were on lockdown, enacting a policy to start staying at home. Start from work, arise the term "work from home". Not only affects adults, apparently, the Covid19 outbreak that has been announced as a pandemic by the World Health Organization since March 11th, 2020, also affects students' learning process. Face-to-face or traditional learning now has turned into a distance learning. According to Bušelić (2012) [1], distance learning is an education field that concentrates on the use of technology to deliver individualized teaching. Students are not physically present in the classroom as usual but "the process that occurs is access to learning when information sources (teachers) and learners are apart by time and distance. The outbreak of the COVID-19 most college students to deal with the distance learning and with hybrid one [2]. 
The distance learning is a separation learning activity between the teacher and students that restricts them to get courses on campus due to time and geographic obstacles [3]. Distance education emphasizes on the use of technology in teaching where the students and the teachers are not in the same place but at certain distance physically [4]. The existence of technology to support learning is not certaint to bring its benefit and its impact on learning process is various [5]. The distance learning is progressively present in ongoing education and hence develops some institutions of education with the guarantee of the quality in distance learning. Distance learning substitutes the learning activity which initially needs a meeting first-handed between students and instructors, becomes meeting virtually through some applications [6]. The social media have been becoming substitute media in teaching wholeworld during the outbreak of the Covid-19 [7-9].

The distance learning [10-11] or distance education or remote learning [12] as a method to teach which is used at the moment, as an alternative method in this pandemic, may help instructors and students. In higher educations, lecturers have some access to dealing with some platfoms of learning like Olat, Moodle, Edmodo, and Atutor to run and manage their learning systems [13-14]. Since there is no sign that the pandemic will halt soon, the education maintains the use of distance learning. The advantages of distance learning are (1) distance learning allows students to create their study plan. It means students can study calmly and comfortably while studying at home. eligibility is provided by classes taught over the internet, nearly all the time, and by using other media [15]. (2) approach to learning opportunity and education can be improved through distance learning, provides increased opportunities for updating, retraining, and private enrichment, improves the cost-effectiveness of educational resources, supports the standard and kind of existing educational structures, improves and strengthens capacity, (3) its usefulness because a lot of the technologies are approachable from home simply that the chance for students to participate on a personal basis whenever they want because of distance learning flexibility, (4) distance learning is additionally multisensory where there's a good type of materials which may be someone's learning option, (5) distance learning can provide developed interactions with students. For introverted students who are too shy to ask questions in school will often "open up" when provided a chance to interact via e-mail or other individualized means [1].

Beside the advantages, the distance learning surely has some disadvantages for both instructors and students. It does not offer quick feedback. In a conventional classroom setting, a student's execution can be immediately evaluated through questions and casual testing, while in the distance learning a student needs to hold up for the response of his/her work by the instructors to counter it (Bušelić, 2012). The issues of distance learning are internal and external and include: (1) the standard of education itself, which is also a factor to be tackled in conventional education; (2) the hidden costs, which are also not adequately classified and may lead to future problems; (3) the misuse of technology, and this issue is important to educational institutions and students; (4) the attitude of instructors, which cannot use the technology related to distance learning and (5) the attitudes of students, who may be less dedicated than students of face-to-face learning [16].

From the previous research, Korolkov, Germanov, Langueva, Shevyakova, \& Poskrebysheva, 2020 studied the advantages and disadvantages of distance learning in the Physical Culture Faculty, they reported that the major downside of distance learning was the absence of social interaction among educational participants. They continued that the major disadvantages of distance learning were the incapability of an instructor to take practical instruction. Practical learning fields such as pharmacy and physical education had a negative impact on the growth 
of practical skills. Another related research stated by [17], the students spent more their time by using gadgets and technology, hence, they had less communication or interaction with both their teachers and friends, and shy students were not accustomed to talking in front of people live. They added that the students who did not learn the given materials were in high possibility, and the test process was not sufficient for them to absorb the materials, as well as to advance their ability of thinking.

Researchers have investigated the disadvantages and negative impacts on the distance learning in developed countries students. However, developing countries students in Indonesia have lack of experiences dealing with the distance learning. The teachers and the students are struggling hard to be successful in the online learning and the result of which is unsatisfactory and even is driving them to learning loss. This article focuses on the drawbacks of distance learning in universities in Indonesia during the outbreak. The research focus was on knowing the impact of distance learning on instructors and students which drive to the distance knowledge and learning lost. There were two questions that would be answered at the end of this article. The first question was what obstacles do the college students experience during the distance learning? The second one is what disadvantages do they get dealing with the distance learning?

\section{Method}

This study used a qualitative research method. Qualitative analysis focused on a variety of methods and provides an interpretive, naturalistic approach to the topic. It means that in their natural environment, qualitative researchers analyze various things, seeking to understand or feel, phenomena in the sense of meaning that people bring to them [18]. The resaerch data were collected through online questionnaire with google forms which containing several questions related to the problems served in this study. The social media used to distribute the questionnaire were Twitter and WhatsApp. With the online questionnaire, there would be increasing number of the participants during the Covid-19 outbreak.

The subject of this study was the college students from different semesters and universities in Indonesia. They have been engaged in distance learning since the Covid-19 outbreaks striking the wold. They have been applied for approximately 10 months or 2 semesters in the universities. The total of participants was fifty-five students. There were nine items in the questionnaire and equipped with participants' data, such as semester, department, and how long they have been engaged in distance learning. The questions lead to college students' complaints about distance learning. The responses of the interview were the explanation of their opinions related to the questions of distance learning.

Figure 1. shows that the highest percentage is the answer "Yes" with $93 \%$ of the college students' lecturers providing materials during distance learning. Otherwise, there are only $7 \%$ of the students who answered "Not all lecturers", which means only a few lecturers who do not provide the materials while having the distance learning.

\section{Findings}

Q2

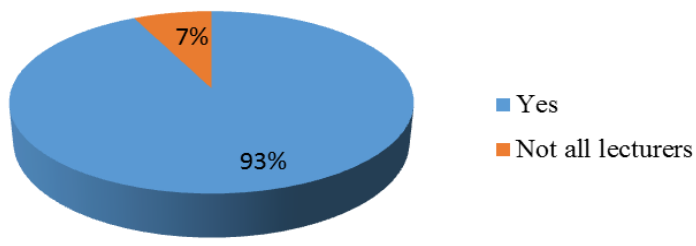


Fig. 1. Pie chart of lecturers providing materials during distance learning

\section{Q3}

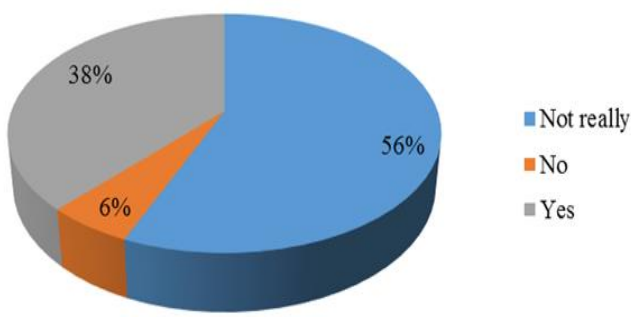

Fig. 2. Pie chart of the students' understanding the materials given by their lecturers

Figure 2. describes the results of the chart of Q3, 56\% of the college students answered "Not really" in understanding the materials given by their lecturers during distance learning. Then, the lowest percentage, 5\% of the students claimed that they don't understand the materials, hence they answered "No". The students who answered "Yes" in understanding the materials given by their lecturers are only $38 \%$.

Table 1. Students' obstacles. They got them during distance learning.

\begin{tabular}{|c|c|c|}
\hline Obstacles & Total & Percentage \\
\hline Poor internet connection & 22 & $40 \%$ \\
\hline Deadline & 3 & $5 \%$ \\
\hline Less focus & 2 & $4 \%$ \\
\hline Limited learning media & 2 & $4 \%$ \\
\hline Blackout & 2 & $4 \%$ \\
\hline Internet data & 1 & $2 \%$ \\
\hline Can't understand the assignments given & 1 & $2 \%$ \\
\hline Unconducive environment & 1 & $2 \%$ \\
\hline Exhausted & 1 & $2 \%$ \\
\hline Survey problems & 1 & $2 \%$ \\
\hline \multicolumn{3}{|l|}{ Multiple reasons: } \\
\hline - Poor internet connection and internet data & 13 & $24 \%$ \\
\hline - Poor internet connection and time corruption (by lecturer) & 2 & $4 \%$ \\
\hline - Poor internet connection and device problem & 1 & $2 \%$ \\
\hline - Poor internet connection and blackout & 1 & $2 \%$ \\
\hline - Poor internet connection, blackout, and internet data & 1 & $2 \%$ \\
\hline - Poor internet connection, internet data, time management & 1 & $2 \%$ \\
\hline
\end{tabular}


Table 1. gives a clear description of the obstacles that are often experienced by the college students during distance learning. From table 1, it can be seen that poor internet connection occupies the highest percentage, 22 students $(40 \%)$ stated that the poor connection was the main problem in distance learning. 3 students $(5 \%)$ answered deadlines of the assignments was the obstacle they faced in distance learning. 2 students $(4 \%)$ stated the obstacle was less focus. 2 students (4\%) answered limited learning media. 2 students (4\%) stated blackout is the obstacle. 1 student $(2 \%)$ stated internet data. 1 student $(2 \%)$ stated that having obstacles in understanding the assignments. 1 student $(2 \%)$ answered the unconducive environment. 1 student $(2 \%)$ answered exhausted. 1 student $(2 \%)$ answered survey problems.

The rest of the participants, 19 students, stated multiple reasons for having the obstacles during distance learning with poor internet connection as the main obstacle. 13 students (24\%) stated that beside the poor internet connection, they also added internet data as the other obstacle. 2 students (4\%) answered poor internet connection, and time corruption committed by the lecturers during distance learning. 1 student $(2 \%)$ had problems with the internet connection and the device. 1 student $(2 \%)$ answered poor internet connection and blackout. 1 student (2\%) answered poor internet connection, blackout, and internet data. 1 student (2\%) had a problem with internet connection, internet data, and time management.

Q5

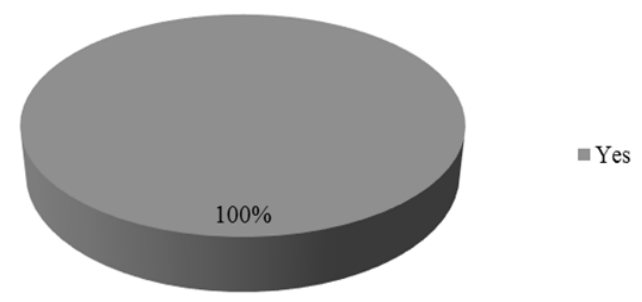

Fig. 3. Pie chart of the students' responses

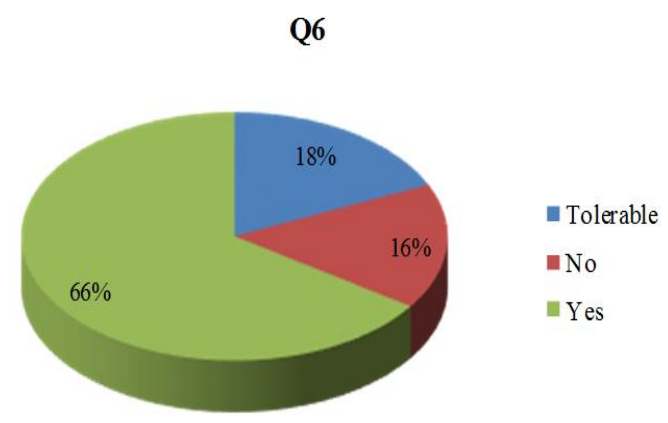

Fig. 4. Pie chart of the Q6 about students' burdensome of the given assignments

Figure 3. describes that 55 participants gave their responses to the question 5 . The college students, answered "Yes" for receiving the assignments from their lecturers during the distance learning. The percentage is $100 \%$ and there is $0 \%$ for the answer "No". 
Figure 4. indicates that the college students mostly answered "Yes" with $66 \%$. It shows that the assignments given by the lecturers were burdensome for the students. There are 13 students added annotations which stated the assignments given were very burdensome, and 9 students stated that the assignments sometimes were burdensome. The answer "Tolerable" is $18 \%$ and there is only $16 \%$ for the answer "No" that thought the assignments from their lecturers were not burdensome for them.

Table 2. Students' obstacles. The obstacles were faced when dealing with assignments given by lecturers.

\begin{tabular}{lcc}
\multicolumn{1}{c}{ Obstacles } & Total & Percentage \\
\hline Can't understand the materials & 19 & $35 \%$ \\
Too many assignments & 13 & $24 \%$ \\
Deadline & 5 & $9 \%$ \\
Difficult to find resources for assignments & 5 & $9 \%$ \\
Poor internet connection & 2 & $3 \%$ \\
Internet data & 1 & $2 \%$ \\
Lack of motivation & 1 & $2 \%$ \\
Difficult to communicate with lecturers & 1 & $2 \%$ \\
Exhausted & 1 & $2 \%$ \\
Miscommunication & 1 & $2 \%$ \\
Doesn't have PC/laptop & 1 & $2 \%$ \\
Time management & 1 & $2 \%$ \\
Environment & 1 & $2 \%$ \\
No obstacle & 1 & $2 \%$ \\
Multiple reasons: & & \\
$\quad$ Too many assignments and tight deadline & 1 & $2 \%$ \\
\hline
\end{tabular}

Table 2. shows the result of the students' obstacles faced with assignments given by their lecturers during distance learning. The highest percentage is 19 students could not understand the materials (35\%), 13 students answered they had been given too many assignments (24\%), followed by deadline (9\%), difficulty in finding valid sources for assignments $(9 \%)$, had problem with poor internet connection (3\%), lack of internet data (2\%), lack of motivation (2\%), difficulty in communicating with lecturers (2\%), exhausted $(2 \%)$, miscommunication $(1 \%)$, did not have PC or laptop (2\%), time management (2\%), environment (2\%), 1 student $(2 \%)$ didn't have obstacle, and 1 student $(2 \%)$ who had multiple reasons; too many assignments and tight deadline.

Table 3. Students' reponses and reasons. They gave their opinions about their lecturers' teaching methods during distance learning.

\begin{tabular}{clcc}
\hline \multicolumn{1}{c}{ Answer and reason } & Total & Percentage \\
\hline Yes & & $\mathbf{1 5}$ & $\mathbf{2 7 \%}$ \\
& More relaxed & 5 & $33 \%$ \\
$\bullet \quad$ Not boring & 5 & $33 \%$ \\
$\bullet \quad$ More effective & 3 & $20 \%$ \\
$\bullet \quad$ Doing assignments at home & 1 & $7 \%$ \\
- $\quad$ Similar with offline system & 1 & $7 \%$ \\
\hline Not really & $\mathbf{1 8}$ & $\mathbf{4 0 \%}$ \\
$\bullet \quad$ Depends on the lecturers & 9 & $50 \%$ \\
$\bullet \quad$ Can't understand the materials & 4 & $22 \%$ \\
$\bullet \quad$ Not effective & 2 & $11 \%$ \\
$\bullet \quad$ Lecturer only giving assignments without teaching & 2 & $11 \%$
\end{tabular}




\begin{tabular}{llcc} 
& - Multiple reasons & & \\
& \multicolumn{1}{c}{ More flexible but can't understand the material } & 1 & $6 \%$ \\
\hline No & & $\mathbf{2 2}$ & $\mathbf{4 0 \%}$ \\
& - Not effective & 11 & $50 \%$ \\
- Can't understand the material & 5 & $23 \%$ \\
- Prefer online learning & 3 & $14 \%$ \\
- Lecturers always use video conference as learning media but the & 1 & $5 \%$ \\
& & & $4 \%$ \\
- & Can't get the learning purpose & 1 & $4 \%$ \\
\hline
\end{tabular}

Table 3. displays the description of Q8. 15 students (27\%) stated that they were satisfied with their lecturers' teaching methods during distance learning. While 18 students $(40 \%)$ stated that they were not really satisfied, it could mean sometimes they were satisfied but sometimes they were not. And then, 22 students $(40 \%)$ stated that they were not satisfied with the learning methods. The students who answered that they were satisfied with the teaching methods stated various reasons. More relaxed (33\%) and not boring (33\%) were the most stated reasons why they were satisfied. Followed by more effective (20\%), doing assignments at home (7\%), and similar with offline system (7\%). Depends on the lecturers $(50 \%)$, could not understand the materials $(22 \%)$, not effective $(11 \%)$ and lecturers only giving assignments without teaching $(11 \%)$ and more flexible but could not understand the materials $(6 \%)$ were the reasons stated by the students who answered they were not really satisfied. Not effective $(50 \%)$, could not understand the material (23\%), prefer online learning (14\%), lecturers always used video conference as learning media but the student had poor internet connection $(5 \%)$, could not get the learning purpose $(4 \%)$ and too many assignments $(4 \%)$ were reasons stated by the students with "not satisfied" answers.

Table 4. Students' reasons. Below things made them stressed during distance learning.

\begin{tabular}{|c|c|c|c|}
\hline & Answer and reason & Total & Percentage \\
\hline Yes & & 30 & $55 \%$ \\
\hline & - Too many assignments & 11 & $37 \%$ \\
\hline & Unconducive learning environment & 3 & $10 \%$ \\
\hline & - Tight deadline & 2 & $7 \%$ \\
\hline & - Can't interact with others & 2 & $7 \%$ \\
\hline & Low grades & 1 & $3 \%$ \\
\hline & $\begin{array}{l}\text { Difficult to understand the material } \\
\text { Multiple reasons: }\end{array}$ & 1 & $3 \%$ \\
\hline & - Too many assignments and can't interact with others & 3 & $10 \%$ \\
\hline & - Too many assignments and tight deadline & 2 & $7 \%$ \\
\hline & Too many assignments and poor internet connection & 1 & $3 \%$ \\
\hline & - Too many assignments and can't understand the material & 1 & $3 \%$ \\
\hline & Too many assignments and time corruption by the lecturer. & 1 & $3 \%$ \\
\hline & $\begin{array}{l}\text { Too many assignments, internet data, poor internet connection, } \\
\text { can't understand the material }\end{array}$ & 2 & $7 \%$ \\
\hline \multicolumn{2}{|c|}{ Not really } & 9 & $16 \%$ \\
\hline \multicolumn{2}{|c|}{ No } & 16 & $29 \%$ \\
\hline
\end{tabular}

Table 4. provides the description of Q9. From the table, it can be seen that more than half of the students $(55 \%)$ are stressed during distance learning. While $16 \%$ stated that they were not 
really stressed (sometimes they were stressed but sometimes they were not) and $29 \%$ stated that they were not stressed. The students who answered that they were stressed had various reasons. The highest percentage of the reason is $37 \%$ which is too many assignments, followed by unconducive learning environment (10\%), tight deadline (7\%), can't interact with others $(7 \%)$, low grades $(3 \%)$, difficult to understand the material $(3 \%)$, and there are 10 students $(33 \%)$ who answered with multiple reasons with the description as written in the table.

Table 5. The college students' perspectives. They tended to have offline learning systems.

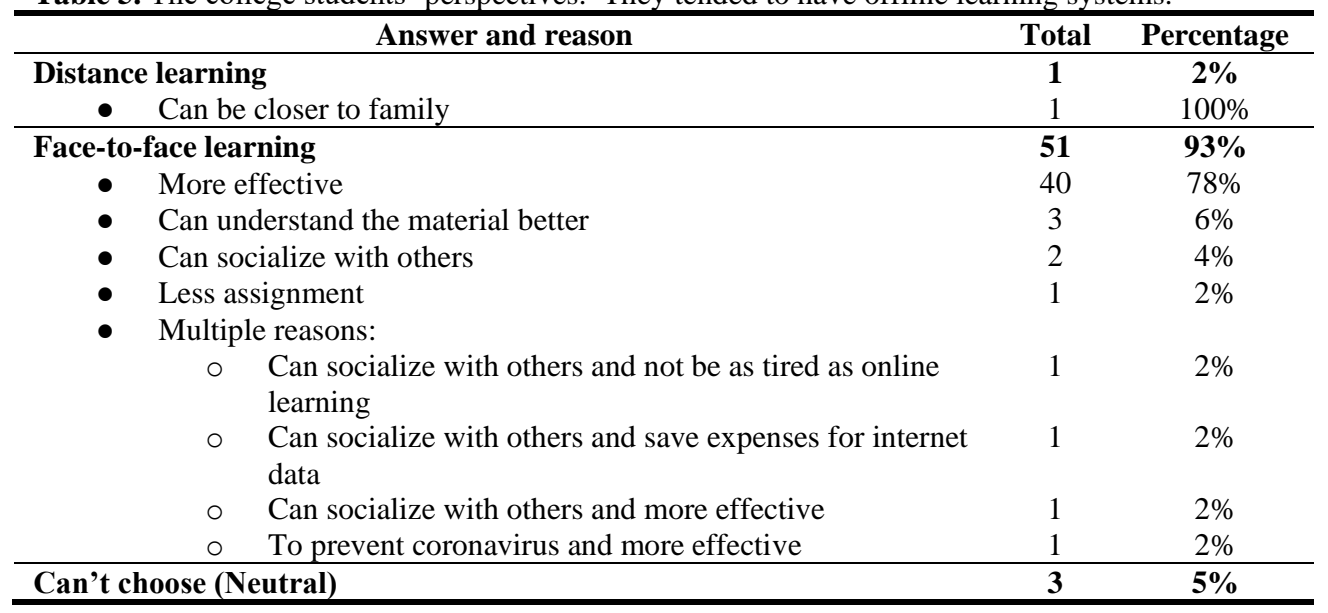

Table 5. shows that the participants mostly chose face-to-face learning (93\%) instead of distance learning (1\%). However, there were 3 participants $(5 \%)$ who were neutral (could not choose among them). 1 student who chose distance learning stated that can be closer to family. The reasons from the students who chose face-to-face learning mostly were more effective $(78 \%)$, followed by can understand the materials better $(6 \%)$, can socialize with others $(4 \%)$, and to prevent coronavirus $(2 \%)$. For the multiple reasons, can socialize and not be more tired (2\%), can socialize and save expenses for internet data $(2 \%)$, can socialize and is more effective (2\%), and to prevent coronavirus and is more effective (2\%).

\section{Discussion}

These results indicate that there are some obstacles that Indonesian college students face during distance learning in this pandemic situation. There are also drawbacks of distance learning. The students who mostly chose distance learning over face-to-face learning experienced various obstacles. The obstacles can lead to various drawbacks that in the end, will affect students' learning process. We highlight the most common obstacles that often appeared in distance learning and their drawbacks.

The obstacles that the students face the most are related to the internet which are poor internet connection and internet data. From the result that the researchers found, these obstacles have the highest percentage among the other obstacles. Internet connection is the most important thing in online learning. As Salac \& Kim, (2016) state that citizen's motivation on newest 
information will decrease due to poor internet connection. This theory will also be the same as the case of college students. With poor internet connection as their obstacle, they will have lack of motivation to participate in online classes. Internet data is also an obstacle that is related to the internet. Internet data also plays a big role in online learning, especially for students that have no Wi-Fi at their home. Without it, students won't be able to participate in online classes. With these internet obstacles as their biggest obstacle in online learning, it prevents students from having good learning experience in distance learning.

Social obstacles are also the obstacles that college students face during online learning. The social obstacles that students face are lack of social interaction with others and an unconducive environment. Due to coronavirus pandemic, it is difficult for students to have real life social interaction among students and teachers. With lack of social interaction, it will be difficult for students to have motivation and achievement outcomes. As Ellwood \& Abrams (2018) found in their research that students' motivation and achievement outcomes will increase if they have real life social interaction. The other social obstacle that college students face is an unconducive environment. From the responses that the researchers got, the unconducive environment is related to the students' home environment. It is difficult for them to learn while they are at home due to many distractions. In order to have effective teaching and learning experience, students need to have a conducive learning environment (Gbadamosi, 2017). Social obstacles that college students face can lead to bad students' motivation, achievement outcomes and ineffective learning experience but it is inevitable during this coronavirus pandemic.

The other obstacles that college students face are related to the lecturers learning system. These obstacles are too many assignments but tight deadlines and students can't understand the material given. From the responses, the researchers found that lecturers give many assignments to the students with tight deadlines and every lecturer gives them assignments with the deadlines at the adjacent time. Students also find it difficult for them to understand the material given since some lecturers only give them assignments without explaining the material. With these obstacles it will be difficult for students to encourage themselves to learn as they did in face-to-face learning.

From the obstacles, there are two drawbacks of distance learning that the researchers found which are distance learning is not effective and students experienced stress. Students who face poor internet connection and internet data obstacles find it difficult to participate in online learning and it makes the learning not effective as they did in face-to-face learning. With the lack and difficulty of social interaction, the online learning process is also not effective. As Dharmaraj (2015) stated that in distance learning, students need to wait for the lecturer to comment on their assignments and cannot directly get the feedback. Having to wait for the feedback makes online learning not effective, especially in time. Students also can't understand the material since the difficulty of interaction they are facing. As seen in the findings, more than half of the college students $(55 \%)$ claim that they are stressed during distance learning. The number of the assignments and the tight deadline given by the lecturer also causes stress to students. Too many assignments that the students must finish make it difficult for them to focus and do the other activities and that leads to stress. The tight deadlines also worsen their stress, one of the examples that resulting high level of stress on students is tight deadlines (Vogel \& Schwabe, 2016). The drawbacks of online learning that the researchers found from the responses of the respondents are based on their experiences. However, another research needs to be done in order to get the better result. 


\section{Conclusion}

In conclusion, from the result of the research, students face many obstacles which are internet obstacles, social obstacles, and obstacles that came from lecturers' learning system. Other than obstacles, the ineffectiveness of social learning and the stress that the students experienced also affect students' learning experience and the students' outcomes. But even though online learning has many disadvantages, for now it is the only possible way for Indonesian college students to learn during this pandemic situation. The obstacles and drawbacks during distance learning cannot be avoided but it can be minimized if the lecturers and students can find the solution of their problems so that the learning process will be more convenient for them.

\section{Acknowledgments}

The researcehrs would like express their great gratitude to the Faculty of Teacher Training and Education, Maritime University of Raja Ali Haji for the valuable support so that they are able to present and publish their article on European Alliance for Innovation. This article is addressed to the college students who have been involved in this research. Without a great collaboration between the instructors and students, this atticle will never exist.

\section{References}

[1] M. Bušelić, „Distance Learning- Concepts and Cntributions,“ Oeconomica Jadertina, p. 23-34, 2012.

[2] L. Vlasenko a N. Bozhok, „eNUFTIR,“ 20 11 2021. [Online]. Available: http://dspace.nuft.edu.ua/jspui/handle/123456789/20684.

[3] F. v. Cappelle, V. Chopra, J. Ackers a P. Gochyyev, „An Analysis of the Reach and Effectiveness of Distance Learning in India during School Closures due to Covid-19,“ International Journal of Educational Development, pp. 1-10, 2021.

[4] W. Al-Mawee, K. M. Kwayu a T. Gharaibeh, „Student's Perspective on Distance Learning during COVID-19 Pandemic: A Case Study of Western Michigan University, United States,“ International Journal of Educational Research Open, pp. 1-13, 2021.

[5] M. Cinelli, W. Quattrociocchi, A. Galeazzi, C. M. Valensise, E. Brugnoli, A. L. Schmidt, P. Zola, F. Zollo a A. Scala, „The COVID-19 Social Media Infodemic,“ Scientific Reports, pp. 1-10, 2020.

[6] R. J. Limaye, M. Sauer, J. Ali, J. Bernstein, B. Wahl, A. Barnhill a A. Labrique, „Building Trust while Influencing Online COVID-19 Content in the Social Media World,“" Lancet Digit Health, pp. $1-2,2020$ 
[7] M. Haman, „The Use of Twitter by State Leaders and its Impact on the Public during the COVID19 Pandemic," Heliyon, pp. 1-9, 2020.

[8] A. Qazi, J. Qazi, K. Naseer, M. Zeeshan, S. Qazi, O. Abayomi-Alli, I. S. Ahmad, M. Darwich, B. A. Talpur, G. Hardaker, U. Naseem, S. Yang a K. Haruna, „Adaption of Distance Learning to Continue the Academic Year Amid Adaption of Distance Learning to Continue the Academic Year Amid," Children and Youth Services Review, pp. 1-6, 2021.

[9] T. Jowsey, G. Foster, P. Cooper-Ioelu a S. Jacobs, „Blended Learning via Distance in Preregistration Nursing Education: A Scoping Review,“Nurse Education in Practice, pp. 1-10, 2020.

[10] N. Cavus, Y. B. Mohammed a M. N. Yakubu, „Determinants of Learning Management Systems during COVID-19 Pandemic for Sustainable Education,“ Sustainability, pp. 1-23, 2021.

[11] S. A. Raza, W. Qazi, K. A. Khan a J. Salam, ,Social Isolation and Acceptance of the Learning Management System (LMS) in the Time of COVID-19 Pandemic: An Expansion of the UTAUT Model,“ Journal of Educational Computing Research, pp. 1-26, 2020.

[12] M. M. S. d. Oliveira, A. S. T. Penedo a V. Pereira, „Distance Education: Advantages and Disadvantages of the Point of View of Education and Society,“ Dialogia, pp. 139-152, 2018.

[13] A. Korolkov, G. Germanov, O. Langueva, A. Shevyakova a N. Poskrebysheva, „Advantages and Disadvantages of Distance Learning on Students' and Teachers' of the Physical Culture Faculty Opinion,“ BIO Web of Conferences, pp. 1-5, 2020.

[14] N. Sokolova, „The Pros And Cons Of Distance Learning,“ The European Proceedings of Social and Behavioural Sciences, pp. 1478-1486, 2018.

[15] P. Aspers a U. Corte, „What is Qualitative in Qualitative Research?,“ Qualitative Sociology, pp. 139-160, 2019.

[16] R. A. Salac a Y. S. Kim, „A Study on the Internet Connectivity in the Philippines, “ Asia Pacific Journal of Business Review, p. 67-88, 2016.

[17] R. Ellwood a E. Abrams, „Student's Social Interaction in Inquiry-Based Science Education: How Experiences of Flow can Increase Motivation and Achievement," Cultural Studies of Science Education, p. 395-427, 2018.

[18] T. V. Gbadamosi, „Students' Unrest: Suggested Measures for Building Peaceful Learning Environment in Public Secondary Schools in Oyo State," Building Safer World through Education, p. 931-946, 2017.

[19] W. Dharmaraj, Centre for Distance Education Learning and Teaching, Bharathidasan University: http://www/bdu.ac.in/cde/docs/ebooks/B- Ed/Learning and Teaching.pdf, 2015. 
[20] S. Vogel a L. Schwabe, „Learning and Memory under Stress: Implications for the Classroom,“ $n p j$ Science of Learning, p. 1-10, 2016.

[21] A. Smalley, „Corescreening,“ Professional Background Screening Association, 2232021. [Online]. Available: https://www.ncsl.org/research/education/higher-education-responses-tocoronavirus-covid-19.aspx. [Cit. 22 November 2021]. 